\title{
Natural product derivative Gossypolone inhibits Musashi family of RNA-binding proteins
}

\author{
Lan Lan ${ }^{1 \dagger}$, Hao Liu ${ }^{1,8+}$, Amber R. Smith ${ }^{1}$, Carl Appelman ${ }^{1}$, Jia Yu ${ }^{1,4}$, Sarah Larsen ${ }^{1}$, Rebecca T. Marquez ${ }^{1}$, \\ Xiaoqing Wu', Frank Y. Liu', Philip Gao², Ragul Gowthaman³ , John Karanicolas', Roberto N. De Guzman', \\ Steven Rogers ${ }^{6}$, Jeffrey Aubé ${ }^{6}$, Kristi L. Neufeld ${ }^{1}$ and Liang $\mathrm{Xu}^{1,7^{*}}$ (D)
}

\begin{abstract}
Background: The Musashi (MSI) family of RNA-binding proteins is best known for the role in post-transcriptional regulation of target mRNAs. Elevated MSI1 levels in a variety of human cancer are associated with up-regulation of Notch/Wnt signaling. MSI1 binds to and negatively regulates translation of Numb and APC (adenomatous polyposis coli), negative regulators of Notch and Wnt signaling respectively.

Methods: Previously, we have shown that the natural product (-)-gossypol as the first known small molecule inhibitor of MSI1 that down-regulates Notch/Wnt signaling and inhibits tumor xenograft growth in vivo. Using a fluorescence polarization (FP) competition assay, we identified gossypolone (Gn) with a > 20-fold increase in Ki value compared to (-)-gossypol. We validated Gn binding to MSI1 using surface plasmon resonance, nuclear magnetic resonance, and cellular thermal shift assay, and tested the effects of $G$ n on colon cancer cells and colon cancer DLD-1 xenografts in nude mice.
\end{abstract}

Results: In colon cancer cells, Gn reduced Notch/Wnt signaling and induced apoptosis. Compared to (-)-gossypol, the same concentration of $G n$ is less active in all the cell assays tested. To increase Gn bioavailability, we used PEGylated liposomes in our in vivo studies. Gn-lip via tail vein injection inhibited the growth of human colon cancer DLD-1 xenografts in nude mice, as compared to the untreated control $(P<0.01, n=10)$.

Conclusion: Our data suggest that PEGylation improved the bioavailability of $\mathrm{Gn}$ as well as achieved tumor-targeted delivery and controlled release of $\mathrm{Gn}$, which enhanced its overall biocompatibility and drug efficacy in vivo. This provides proof of concept for the development of Gn-lip as a molecular therapy for colon cancer with MSI1/MSI2 overexpression.

Keywords: Gossypolone, Musashi, RNA-binding protein, Colon cancer, Liposomes

\section{Background}

The expression of the RNA-binding protein Musashi-1 (MSI1) is elevated in a variety of human cancers, including glioblastoma, breast, colon and lung cancers [1-10], with higher levels corresponding to poor prognosis $[3-5,10-12]$. Msi1 was first identified in Drosophila where it plays a role in neural development and asymmetric cell division in the

\footnotetext{
* Correspondence: xul@ku.edu

${ }^{\dagger}$ Lan Lan and Hao Liu contributed equally to this work.

'Departments of Molecular Biosciences, University of Kansas, 4002 Haworth Hall, 1200 Sunnyside Avenue, Lawrence, KS 66045-7534, USA

${ }^{7}$ Department of Radiation Oncology, University of Kansas Cancer Center, Kansas City, Kansas, USA

Full list of author information is available at the end of the article
}

adult sensory organ [13]. Subsequently, Msi1 homologs were identified in other species, with higher levels in stem and undifferentiated cells $[1,2,14-17]$. Musashi- 1 typically plays a role in post-transcriptional regulation of target mRNAs [18-22]. Up-regulation of MSI1 in cancers appears to associate with elevated Notch/Wnt signaling, as MSI1 targets Numb [22, 23] and APC (adenomatous polyposis coli) [19] are negative regulators of Notch and Wnt signaling, respectively $[24,25]$. CDKN1A (P21), a negative regulator of cell cycle progression, is also a direct MSI1 target [21]. In all three cases, MSI1 blocks target mRNA translation. Knocking down MSI1 using siRNA [3], miRNA [26] and a small molecule inhibitor [27] led to decreased xenograft tumor

(c) The Author(s). 2018 Open Access This article is distributed under the terms of the Creative Commons Attribution 4.0 International License (http://creativecommons.org/licenses/by/4.0/), which permits unrestricted use, distribution, and reproduction in any medium, provided you give appropriate credit to the original author(s) and the source, provide a link to the Creative Commons license, and indicate if changes were made. The Creative Commons Public Domain Dedication waiver (http://creativecommons.org/publicdomain/zero/1.0/) applies to the data made available in this article, unless otherwise stated. 
growth. Taken together, these results point to MSI1 as a potential therapeutic target.

Our previous study identified (-)-gossypol as a small molecule inhibitor of MSI1 that reduced cancer cell proliferation and xenograft growth [27]. More recent screening in our lab using an FP assay revealed more potent and/or specific inhibitors of MSI1. One inhibitor with a Ki of $12 \pm 2 \mathrm{nM}$ against full length MSI1 was gossypolone $(\mathrm{Gn})$, it had a higher affinity than (-)-gossypol $(\mathrm{Ki}=476 \pm 273 \mathrm{nM})$ [27]. Gn also showed similar affinity towards Musashi-2 (MSI2) in FP assay ( $\mathrm{Ki}=7.0 \pm 0.3 \mathrm{nM}$ against full length MSI2). MS12 is another Musashi family member that plays both redundant and independent roles as MSI1 in neural stem cells [28, 29]. In cancer, MSI2 expression is elevated in hematologic malignancies [30-36], colorectal adenocarcinomas [37], lung [38], pancreatic cancers [39-41], and glioblastoma [42]. MSI1 and MSI2 share sequence and structure similarity, especially their N-terminal RNA recognition motifs (RRMs). The residues that recognize $\mathrm{r}(\mathrm{GUAGU})$ are highly conserved between MSI1 and MSI2 [43]. Thus, Gn can potentially be used as a MSI1/2 dual inhibitor.

$\mathrm{Gn}$ is a major metabolite of gossypol [44], and is oxidized in the liver by P450 enzyme [45]. Gn shares similar biological activities as gossypol [46-52], including as an inhibitor of Bcl-2 family with a Ki of $0.28 \mu \mathrm{M}$ toward Bcl-xL [49]. However, in colon cancer cell assays, the same concentration of Gn was less potent than (-)-gossypol [27].

To address this problem, we introduce a new liposome-based Gn nanocarrier. Liposomes have long been used as nanocarriers for targeted cancer therapy and have demonstrated biocompatibility and controlled drug release in previous studies [53-56]. Particularly, compared with unmodified liposomes, some PEGylated liposomes were reported to be less entrapped by reticuloendothelial cells and lead to enhanced drug delivery to solid tumors in vivo [57-59]. In the present study, PEGylated liposomes were used to improve the bioavailability of $\mathrm{Gn}$ as well as to achieve tumor-targeted delivery and controlled release of $\mathrm{Gn}$, which enhances its overall biocompatibility and drug efficacy in vivo.

\section{Methods}

\section{Cell culture and reagents}

Human colon cancer cell lines HCT-116, HCT-116 $\beta / \mathrm{W}$ and DLD-1, are as described by Lan et al. [27] and tested for mycoplasma contamination [60] before use.

Gossypolone (Gn) was prepared as previously described [61]. (3, 4-Dimethoxyphenyl)methanimine gossypol (MP -Gr) was synthesized from gossypol [27]. The $\mathrm{Gn}$ and MP-Gr powder were dissolved in DMSO at $20 \mathrm{mM}$ as stock solutions. L- $\alpha$-phosphatidylcholine (EPC) and 1,2-distearoyl-sn-glycero-3-phosphoethanolamine- $\mathrm{N}$-[methoxy(po lyethylene glycol)-2000] (PEG-DSPE) were purchased from
Avati Polar Lipids, Inc. (Alabama, USA) . DiR (1,1'-dioctadecyl-3,3,3',3' -tetramethylindotricarbocyanine iodide) was purchased from Invitrogen (Carlsbad, CA).

Cell growth, MTT, colony formation, western blot analysis, Caspase- 3 activation assay, RT-PCR and quantitative real-time PCR were carried out according to our previous publications [27, 62-66]. Protein expression and purification, FP competition assay, SPR, NMR, and Wnt luciferase reporter assay were carried out as previously described [27]. The primer sequences, the primary and the secondary antibodies used were from Lan et al. [27]. Live cell imaging was carried out using EVOS FL Auto Cell Imaging System (Invitrogen, Thermo Fisher Scientific) and images were cropped and processed using Image (NIH).

For all cell based studies, the DMSO concentration was $0.1 \%$ except where indicated below (for CETSA).

\section{Computational modeling}

The AutoDock4.2.6 program [67] was used for docking calculations. The three-dimensional structure of Musashi1's RBD1 in complex with RNA (PDB: 2RS2) was used to dock the gossypolone compound at the MSI1 RBD1 - RNA interface. A grid box of size $40 * 44 * 56 \AA$ with $0.375 \AA$ spacing centered around residue F23 was used for docking. A total of 200 docking runs were carried out using the Lamarckian genetic algorithm. The docked conformation with lowest energy was selected as the final predicted binding mode.

\section{Cellular thermal shift assay (CETSA)}

CETSA was carried out according to Molina et al. [68]. For Gn dose CETSA, the HCT-116 $\beta / \mathrm{W}$ cell lysates with different concentrations of $\mathrm{Gn}$ were incubated for $30 \mathrm{~min}$ and heated individually at $52{ }^{\circ} \mathrm{C}$ for $3 \mathrm{~min}$ (StepOnePlus ${ }^{\text {тм }}$ Real-Time PCR System, Applied Biosystems/Life Technologies) followed by cooling for $3 \mathrm{~min}$ at $25{ }^{\circ} \mathrm{C}$. The soluble fractions were analyzed by western blot. The concentration of DMSO in each sample is 3.3\%. Musashi-1 antibody used for CETSA was anti-MSI1 (01-1041, Millipore, Billerica, MA). Western band intensities were measured using Image Studio Ver 4.0 (LI-COR Bioscience, Lincoln, NE), and normalized to $\alpha$-Tubulin.

\section{Preparation and characterization of gossypolone- encapsulated liposomes (Gn-lip)}

Gn-lip was formed using a mixture of $\mathrm{Gn}, \mathrm{EPC}$, PEG-DSPE, and cholesterol in chloroform, at a molar ratio of $30 / 85 / 6 / 9$. The solution was dried under vacuum to form a thin film of $\mathrm{Gn} /$ carrier mixture, which was then dissolved in DPBS to produce Gn-encapsulated liposomes. Blank liposomes were prepared similarly without the addition of Gn. To prepare the samples for TEM image, both $\mathrm{Gn}$-lip and blank liposomes were diluted in DI water, respectively. The suspensions were applied to 
a grid and negatively stained by $4 \%$ uranyl acetate. Images of liposomes were acquired using FEI Tecnai G2 Polara 200 kV TEM (FEI Company, OR, USA). The size distribution and zeta potential of liposomes in DI water were measured at $25 \mathrm{C}$ using a Malvern instrument (Nano-ZS90, Malvern, UK). The size stability of Gn-lip for 3 months was investigated at $4{ }^{\circ} \mathrm{C}$. The drug loading efficiency (DLE\%) and drug loading content (DLC\%) of Gn were determined using filtration method. Gn-lip solution was filtered using an ultra centrifugal filter unit (MWCO 3000 Da, Amicon ${ }^{\oplus}$, Merck KGaA, Germany). The concentration of free drug in the filtrate was determined using a UV-vis spectrophotometer. The DLE\% and DLC\% of Gn were calculated as follows: DLE\% = (weight of loaded Gn $\div$ total weight of input Gn) $\times 100 \%$; DLC\% $=($ weight of loaded $\mathrm{Gn} \div$ total weight of Gn-lip) $\times 100 \%$.

The viabilities of HCT-116 and DLD-1 cells in the presence of free $\mathrm{Gn}$ or $\mathrm{Gn}$-lip were determined using MTT-based assay, as described previously.

\section{Biodistribution of DiR-loaded liposomes in tumor-bearing mice}

NOD.CB17-Prkdcscid (SCID) mice were purchased from Harlan laboratory (Indianapolis, IN) and bred at the University of Kansas Animal Care Unit. The in vivo tumor-specific distribution of liposomes was studied using DiR, a near-infrared (NIR) fluorescent dye. DiR-loaded liposome was formed using a mixture of DiR, EPC, PEG-DSPE, and cholesterol in chloroform, at a molar ratio of $1 / 85 / 6 / 9$. The solution was dried under vacuum to form a thin film of DiR/carrier mixture, which was then dissolved in DPBS to produce DiR-loaded liposomes. Two DLD-1 tumor-bearing SCID mice were used for in vivo fluorescence imaging according to our previous studies with modifications $[69,70]$. Briefly, $10 \mathrm{nmol}$ DiR-loaded liposome in $200 \mu \mathrm{L}$ was intravenously (i.v.) injected into one mouse; $200 \mu \mathrm{L} 10 \mathrm{nmol} \mathrm{DiR}$ ethanol/water $(1: 4 v / \mathrm{v})$ mixed solvent as the control was $i . v$. injected into another mouse. At different time points, the biodistributions of $\mathrm{DiR}$ in both mice were observed using a Carestream Molecular Imaging System (Carestream Health, Rochester, $\mathrm{NY}$ ), with excitation at $750 \mathrm{~nm}$ and emission at $830 \mathrm{~nm}$ using an exposure time of $60 \mathrm{~s}$. Mice were euthanized at $72 \mathrm{~h}$ post-injection by $\mathrm{CO} 2$ overdose and confirmed by cervical dislocation as recommended by the Panel on Euthanasia of the American Veterinary Medical Association. Organs and tumors of mice were obtained for further ex vivo fluorescence imaging. The fluorescence intensities of tumors at different time point in vivo, and tumors and livers ex vivo, were quantified using the 'Image Math' function of Carestream Molecular Imaging Software (Carestream Health, Inc). To produce calibration curves for DiR-lip and free DiR, $50 \mu \mathrm{L}$ DPBS containing different amount of DiR-lip or free DiR was added in each well of a 96-well plate, followed by in vitro imaging using the same settings with that of the in vivo imaging. The calibration curves were produced using the fluorescence intensity of each well. The amount of dye in each tissue was calculated using its fluorescence intensity and the corresponding calibration curve. The fluorescence percentage of injected dose per gram $(\% \mathrm{ID} / \mathrm{g})$ of each tissue was calculated using the following formula:

$$
\% \mathrm{ID} / \mathrm{g}=\frac{\mathrm{M}_{\mathrm{DiR}}}{\mathrm{ID} \times \mathrm{W}_{\text {Tissue }}} \times 100 \%
$$

in which $M_{D i R}$ is the amount (nmol) of DiR in the tissue, ID is the injected amount (nmol) of DiR, and $\mathrm{W}_{\text {Tissue }}$ is the weight ( $\mathrm{g}$ ) of tissue.

\section{In vivo drug efficacy of Gn in DLD-1 tumor-bearing nude mice}

The in vivo experiments were carried out with 5 to 6-week-old female athymic $\mathrm{NCr}$-nu/nu nude mice purchased from the Harlan laboratory (Indianapolis, IN). After alcohol preparation of the skin, mice were inoculated subcutaneously with $200 \mu \mathrm{L}$ DLD-1 cell suspension $\left(1 \times 10^{6}\right.$ cells $)$ in plain DMEM on both flanks using a sterile 23-gauge needle. When tumors reached $40 \mathrm{~mm}^{3}$ on average, the mice were randomized into 2 groups. Group 1 (10 mice, 20 tumors) was given vehicle as the control; group 2 (5 mice, 10 tumors) was given $10 \mathrm{mg} / \mathrm{kg}$ Gn-lip. Gn-lip was administrated intravenously 2 times weekly for 3.5 weeks. Tumor size and body weight of each mouse were measured twice a week, and tumor volumes were determined as $a \times b^{2} / 2$, in which $a$ and $b$ represent the longest and shortest diameter of the tumors, respectively. All animal experiments were carried out according to the protocol approved by the Institutional Committee for the Use and Care of Animals of University of Kansas.

\section{Statistical analysis}

Using Prism 5.0 software (GraphPad Prism), one-way ANOVA and $t$-Test were used to analyze the in vitro data, two-way ANOVA was used to analyze the in vivo data. A threshold of $P<0.05$ was defined as statistically significant.

\section{Results}

Gossypolone disrupts the Musashi-numb RNA interaction In our previous screen for small molecule inhibitors of MSI1-Numb RNA binding using FP competition assay, we identified and validated (-)-gossypol as an effective inhibitor that disrupts MSI1-RNA binding [27]. We also identified gossypolone $(\mathrm{Gn})$ as a potent disruptor of MSI1-Numb RNA binding, with more than 20-fold higher affinity than that of (-)-gossypol under the same experimental condition (Ki $13 \pm 5 \mathrm{nM}$ vs $476 \pm 273 \mathrm{nM}$ ) [27]. Figure 1a showed that Gn dose dependently inhibits MSI1 


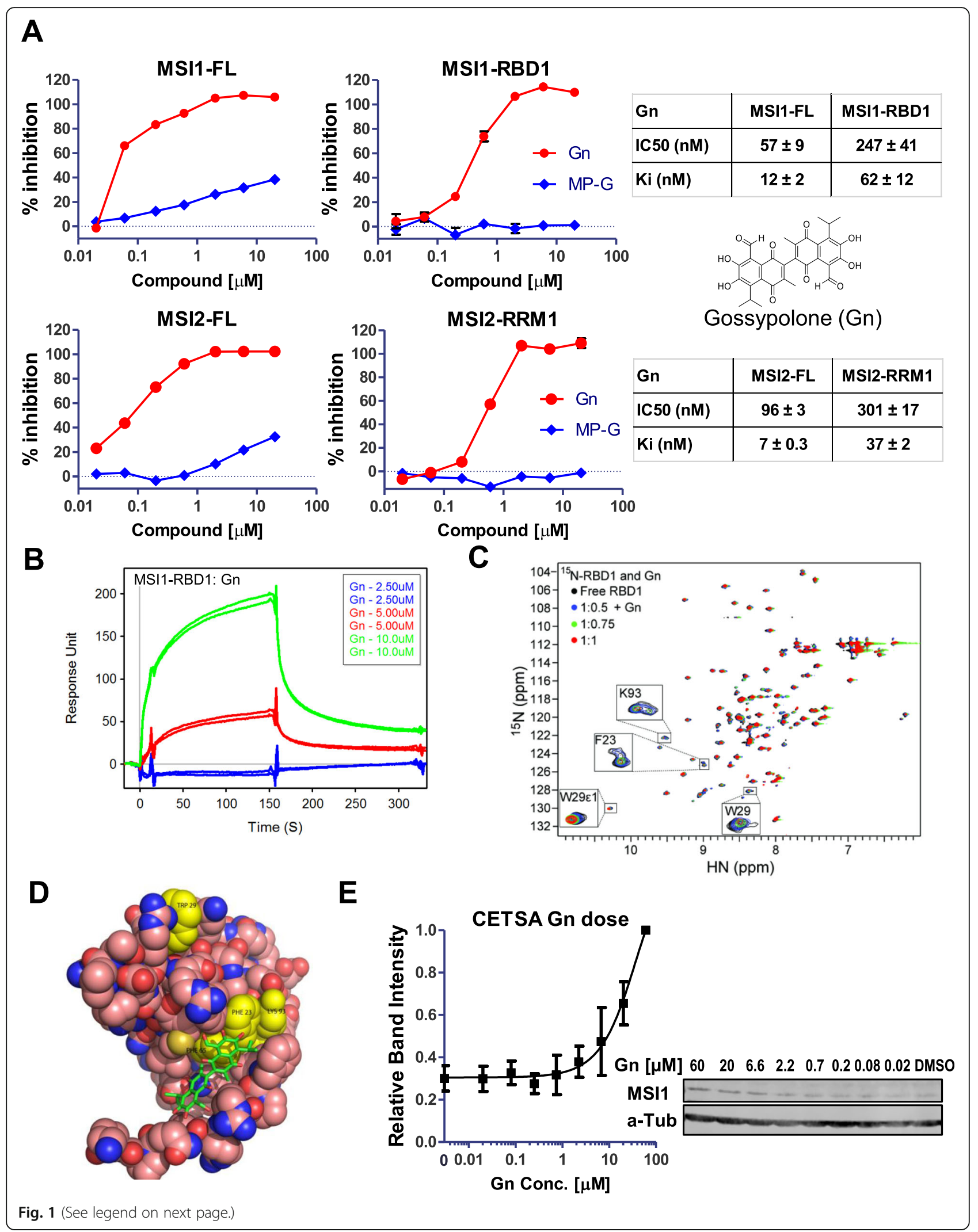




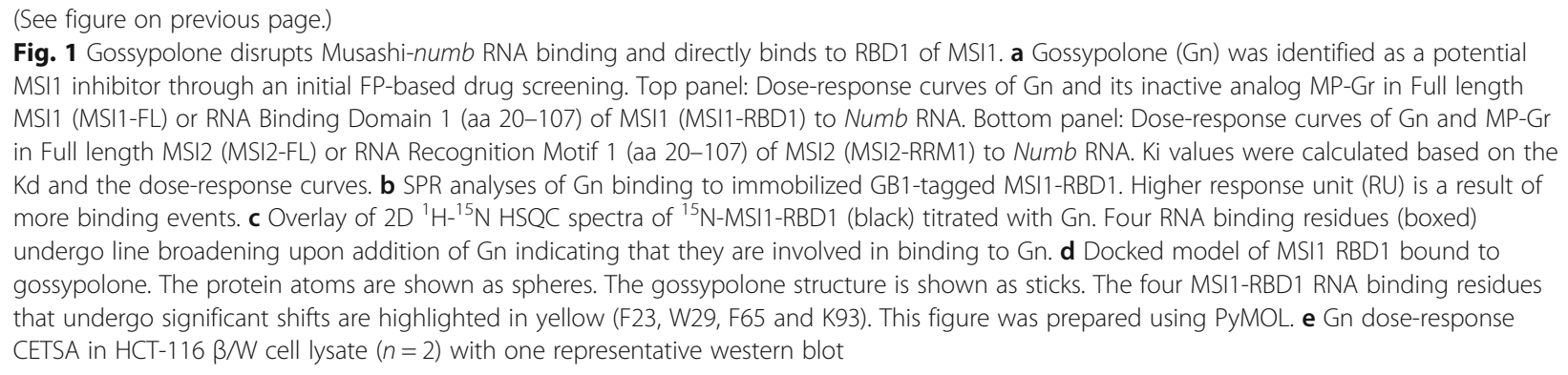

from binding to a fluorescein labeled $N u m b$ RNA (5'-UAGGUAGUAGUUUUA-3'), with Ki of $12 \mathrm{nM}$ and $62 \mathrm{nM}$ to full length MSI1 (MSI1-FL) and RNA-Binding Domain 1 (RBD1) of MSI1 (MSI1-RBD1) respectively. As a control, MP-Gr, which is structurally related to $\mathrm{Gn}$ and (-)-gossypol, showed a Ki of larger than $200 \mu \mathrm{M}$ (Fig. 1a top panel, [27]). Because of the conserved residues in N-terminal RRMs of MSI1 and MSI2 [43], the same Numb RNA in our MSI1 FP assay also binds to MSI2-FL and MSI2-RRM1 (data not shown). Figure 1a bottom panel showed that Gn disrupted MSI2-Numb RNA binding, with $\mathrm{Ki}$ of $7 \mathrm{nM}$ and $37 \mathrm{nM}$ to full length MSI2 and MSI2-RRM1 respectively. Our data demonstrate that Gn disrupts MSI1/MSI2-Numb RNA binding and can potentially work as a MSI1/MSI2 dual inhibitor.

\section{Gossypolone directly binds to the RBD1 of MSI1 protein}

To confirm the direct binding of Gn to MSI1, we carried out additional assays. First, we tested Gn in a SPR-based binding assay. In SPR, GB1-tagged MSI1-RBD1 was immobilized on the sensor chip and the level of response increases with increasing amount of material bound to the surface. As shown in Fig. $1 \mathrm{~b}$, at $5 \mu \mathrm{M}$, the response was 50 , while at $10 \mu \mathrm{M}$, the response was 200. The SPR assay showed that Gn binds to MSI1-RBD1 in a dose-dependent manner.

The binding of Gn to MSI1-RBD1 was also confirmed using NMR (Fig. 1c). Results of NMR titrations of ${ }^{15} \mathrm{~N}$ MSI1-RBD1 with Gn showed that the RNA-binding residues (K93, F23, and W29) were primarily affected by Gn (Fig. 1c). The backbone amide peaks of K93, F23, and W29; including the side chain peak of W29, showed changes in peak positions as well as decreased peak intensities with increasing amounts of $\mathrm{Gn}$, whereas most non-RNA binding residues remained unaffected. These NMR results suggested that these residues are involved in the binding of $\mathrm{Gn}$ to the RNA-binding pocket of MSI1-RBD1. Using computational docking, we then built a model of $\mathrm{Gn}$ bound to the RNA-binding pocket of MSI1-RBD1 (Fig. 1d); this model is in agreement with the NMR observation that these particular residues (K93, F23 and W29) are responsible for the interaction of MSI1-RBD1 with Gn.

\section{Gn targets MSI1 in cells}

To test drug-target engagement in cells, we used the CETSA to determine the thermal stability of target protein MSI1. When a protein is stabilized with addition of a ligand, the bound proteins can stay in solution whereas unbound proteins denature and precipitate with increasing temperatures [68]. The advantage of CETSA is that one can evaluate the compounds in a cellular context, thus allowing us to identify the compounds with poor bioavailability that otherwise have high affinity in biochemical assays. Fig. 1e showed the concentration-dependent target engagement of Gn with MSI1, that is, more MSI1 protein is stabilized at higher $\mathrm{Gn}$ concentration.

\section{Gn inhibits cell proliferation, induces apoptosis and autophagy in colon cancer cell lines}

Previous studies have pointed to a tumorigenic role for MSI1, with overexpression of MSI1 leading to tumorigenesis in a mouse xenograft model [71], and decreased MSI1 leading to reduced tumor progression $[3,4,10]$. Our in vitro biophysical binding studies revealed a role of $\mathrm{Gn}$ in disrupting the RNA-binding ability of MSI1. We hypothesized that such disruption would lead to a de-repression of MSI1 target mRNA translation, thus decreased Notch/Wnt signaling and decreased cell growth. To investigate the effect of $\mathrm{Gn}$ in cells, we first assayed the overall growth of colon cancer cells with Gn treatment. As shown in Fig. 2, compared to negative controls DMSO or MP-Gr [27], $10 \mu \mathrm{M}$ Gn treatment led to a significant decrease in cell growth in three colon cancer cell lines tested (Fig. 2a), colony formation assays also confirmed that there were fewer colonies formed with higher concentrations of Gn (Fig. 2b). Gn treatment phenocopied the cell growth assay and colony formation assay results obtained with HCT-116 $\beta / \mathrm{W}$ MSI1 CRISPR knockout clones (Fig. 2c, Additional file 1: Figure S1) and HCT-116 $\beta / \mathrm{W}$ MSI1 shRNA knock down clones (data not shown).

We next tested whether Gn treatment will induce apoptosis and/or autophagy in cells. We examined PARP cleavage and Caspase- 3 activation in two colon cancer cell lines. As shown in Fig. 3a-b, at $10 \mu \mathrm{M}$, Gn led to increased PARP cleavage (Fig. 3a), as well as augmented Caspase-3 activation (Fig. 3b); while MP-Gr or DMSO did not show any 


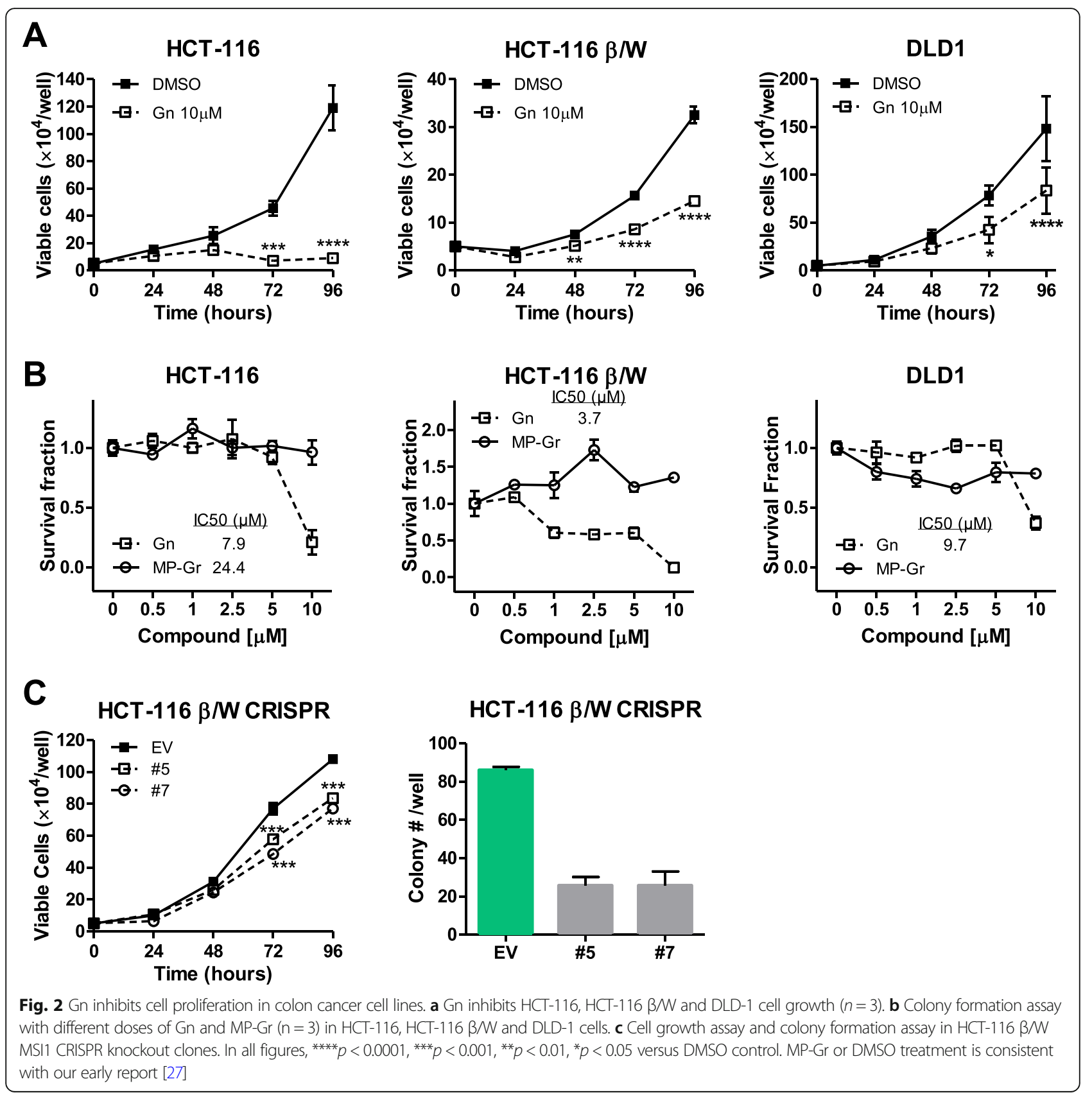

effect, consistent with our early report [27]. These data indicate that $\mathrm{Gn}$ induces apoptosis in colon cancer cell lines. Using a live cell image system, we showed that $20 \mu \mathrm{M}$ Gn induced autophagy in DLD-1 cells and led to cell death via apoptosis (Additional file 2: Video 1 and Additional file 3: Video 2). One representative view from the video in each treatment was presented in Fig. 3c. The cell treated with $20 \mu \mathrm{M}$ Gn started to accumulate autophagosome after $14 \mathrm{~h}$, and died via apoptotic cell death (Fig. 3c left panel). In contrast, cells with DMSO control proliferated and covered the whole view at the end of the time lapse $(72 \mathrm{~h}$ ) (Fig. 3c right panel). Additionally, autophagy induction was shown by the LC3 conversion and P62 degradation [72] in Gn treated samples (Fig. 3d). When we pretreated the cells with chloroquine (CQ), an autophagy inhibitor that blocks the fusion of autophagosome with lysosome and lysosomal protein degradation [73], p62 degradation was blocked (Fig. 3d). These data indicate that Gn induces efficient autophagic flux, and leads to apoptotic cell death.

Gn down-regulates Notch/Wnt signaling through MSI1

As describe above, binding assays showed that $\mathrm{Gn}$ bound to RBD1 of MSI1 and potentially blocked MSI1-target mRNAs binding, which would presumably lead to changes 
A
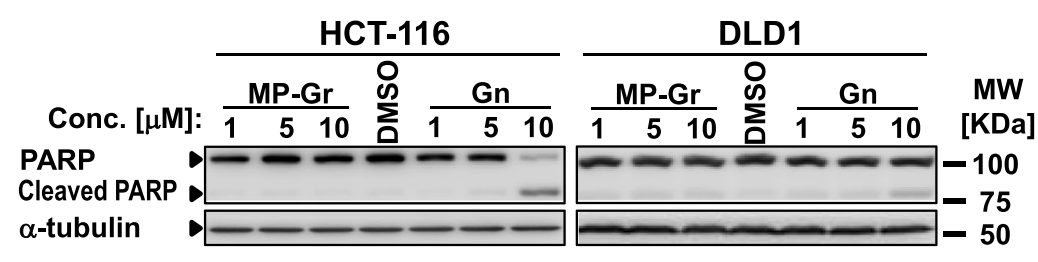

B

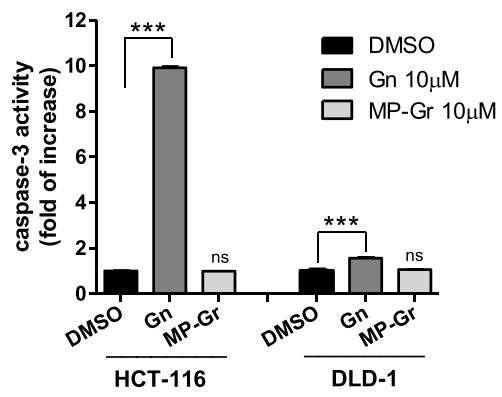

D

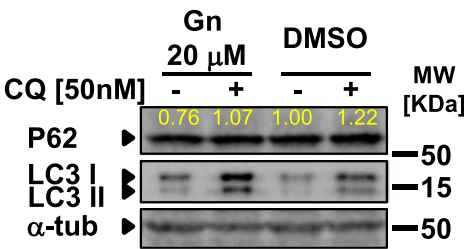

DLD-1

C

DLD-1: Gn $20 \mu M$
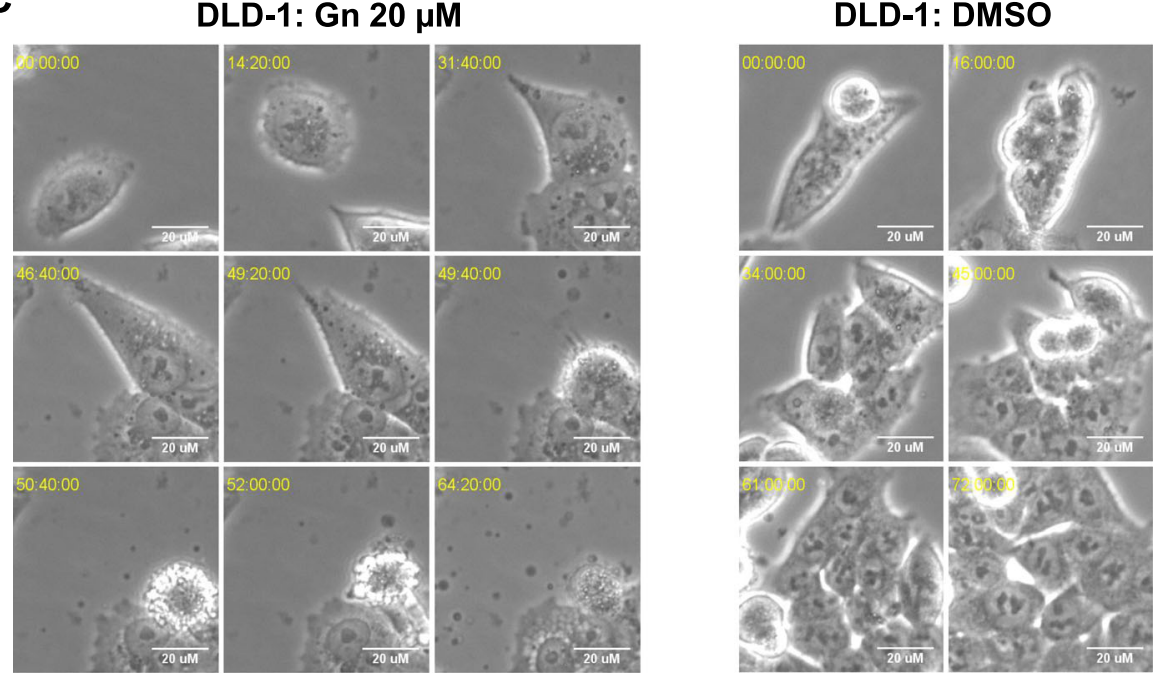

Fig. $3 \mathrm{Gn}$ induces apoptosis and autophagy in colon cancer cell lines. a PARP cleavage was observed in colon cancer cell lines treated with different doses of Gn for 48 h. MP-Gr or DMSO treatment had no effect, consistent with our early report [27]. b Caspase-3 activity was increased in Gn treated cells. MP-Gr or DMSO treatment had no effect, consistent with our early report [27]. $(n=2) .{ }^{* * *} p<0.001$ versus DMSO control. c Representative images of Gn or DMSO treated DLD-1 cells from time lapse videos. d DLD-1 cells were treated with Gn or DMSO, in the presence or absence of chloroquine (CQ, $50 \mathrm{nM})$ pretreatment for $16 \mathrm{~h}$

in MSI1 downstream targets. To test this idea, we examined the levels of several proteins and mRNAs upon Gn treatment. We noticed an increase in P21 protein level with $\mathrm{Gn}$ treatment in both colon cancer cell lines tested (Fig. 4a). P21 is a direct binding target of MSI1 [21], Gn binding to MSI1 would release P21 from its translation repression. However, we saw an increase in P21 mRNA level as well (Fig. 4b), which may potentially be due to other effects of Gn not related to MSI. Gn is an active metabolite of (-)-gossypol, and we and others previously reported (-)-gossypol as a Bcl-2 inhibitor [62, 63, 74-76]. The increase in P21 mRNA level could be due to Bcl-2 related functions of $\mathrm{Gn}$. With Gn treatment, we observed decreases in other MSI1 downstream targets as well. These included c-MYC, CCND1 (CYCLIN D1) and BIRC5 (SURVIVIN), all of which are downstream of Notch/Wnt pathways. Additionally, we detected decreases in MSI1 protein and mRNA levels, such reductions are results of decreased Wnt signaling, as MSI1 is a Wnt target $[19,71]$. To evaluate the Gn's ability in inhibiting Wnt signaling, we used a TOP/FOP reporter assay. As shown in Fig. 4c, Gn dose-dependently inhibited the reporter activity. Taken together, our data indicate that Gn down-regulates Notch/ Wnt signaling.

Compare with (-)-gossypol, Gn was less effective in downregulating Notch/Wnt signaling through MSI1 in cells. For example, Wnt target gene AXIN2 mRNA levels were $50 \%(10 \mu \mathrm{M}$ Gn treatment) versus $20 \%(10 \mu \mathrm{M}$ 
A

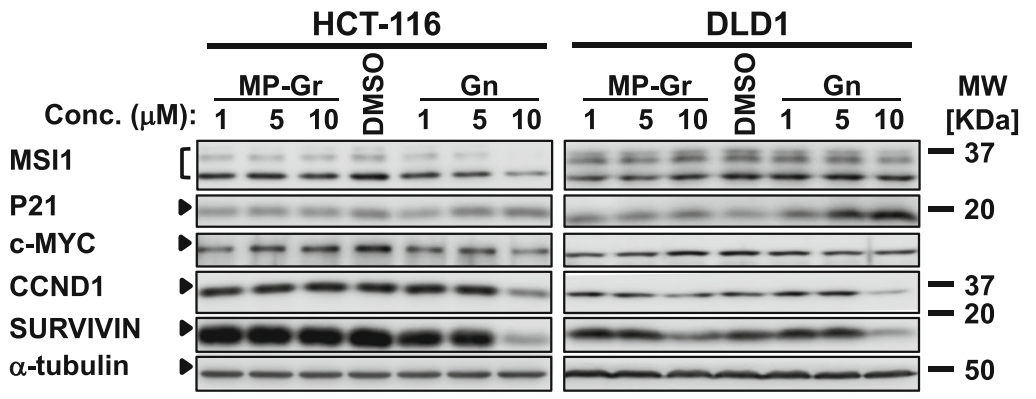

B
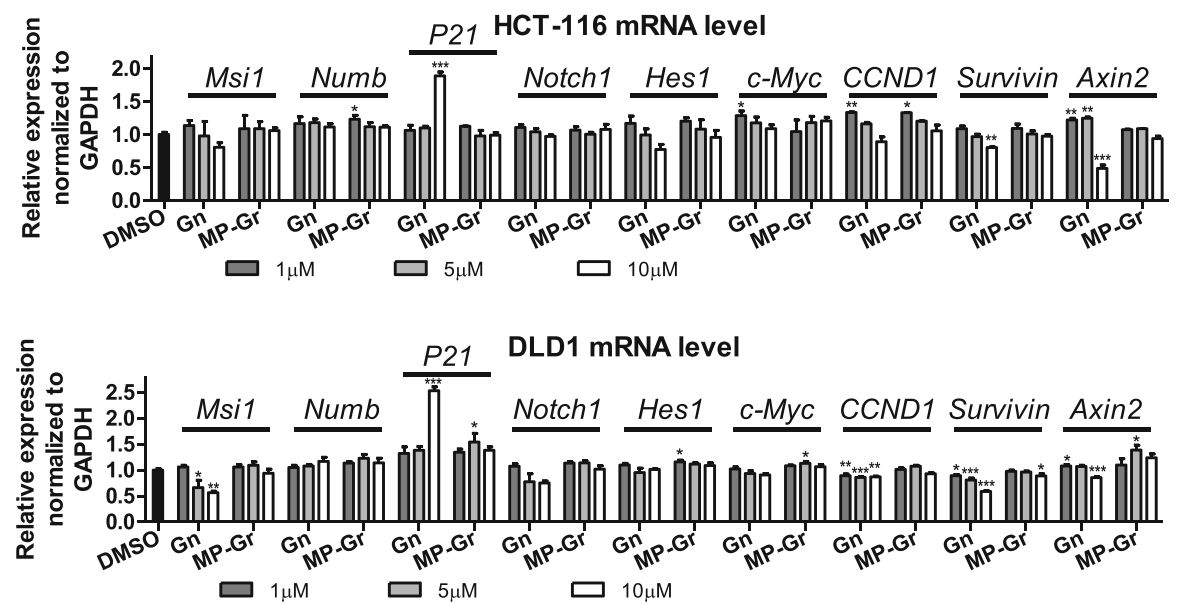

C

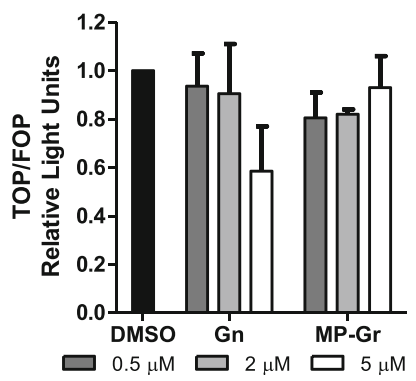

Fig. 4 Gn down-regulates Notch/Wnt signaling. In HCT-116 and DLD1 cells, Notch and Wnt target genes expression in protein (a) and mRNA (b) levels were altered upon drug treatment. For protein detection, cells were collected $48 \mathrm{~h}$ after drug treatment; for real-time RCR, cells were collected $24 \mathrm{~h}$ after treatment. c TOP flash Wnt signaling reporter assay was carried out in HCT-116 cells with DMSO or different doses of drugs. In all Figures, ${ }^{* * * *} p<0.0001,{ }^{* * *} p<0.001,{ }^{* *} p<0.01,{ }^{*} p<0.05$ versus DMSO control. MP-Gr or DMSO treatment is consistent with our early report [27]

(-)-gossypol treatment) compared to DMSO control (set as 1) in HCT-116 cells, and $80 \%$ versus $40 \%$ in DLD-1 cells (Fig. 4b, [27]). In our biophysical assays, Gn showed a better affinity to MSI1 (Fig. 1a, [27]). We thus sought to introduce a carrier for delivering $\mathrm{Gn}$ in vivo.

\section{Characterizations of Gn-lip}

The morphology of Gn-loaded liposomes (Gn-lip) and blank liposomes was observed using transmission electron microscopy (TEM). Both Gn-lip and blank liposomes exhibited a similar spherical shape (Fig. 5a and b on the left). Some shrinkage was also observed in larger liposomes. No obvious difference was found between the two samples. Also, both liposomes possessed similar dynamic sizes around $56 \mathrm{~nm}(55.89 \pm 0.34 \mathrm{~nm}$ for Gn-lip and $56.03 \pm 0.42 \mathrm{~nm}$ for blank liposomes) and Zeta-potential around zero $\mathrm{mV}(-0.04 \pm 0.06 \mathrm{mV}$ for Gn-lip and $0.83 \pm 0.46 \mathrm{mV}$ for blank liposomes) as determined by Dynamic Light Scattering (DLS). The morphology and surface charge of liposomes were not affected by the Gn encapsulation. The DLE\% and DLC\% of Gn were $80.74 \% \pm 0.77$ and $13.22 \% \pm 0.11 \%$, respectively, respectively. After storage at $4{ }^{\circ} \mathrm{C}$ for 3 months, the particle size of Gn-lip was $62.97 \pm 1.65 \mathrm{~nm}$, which was near 

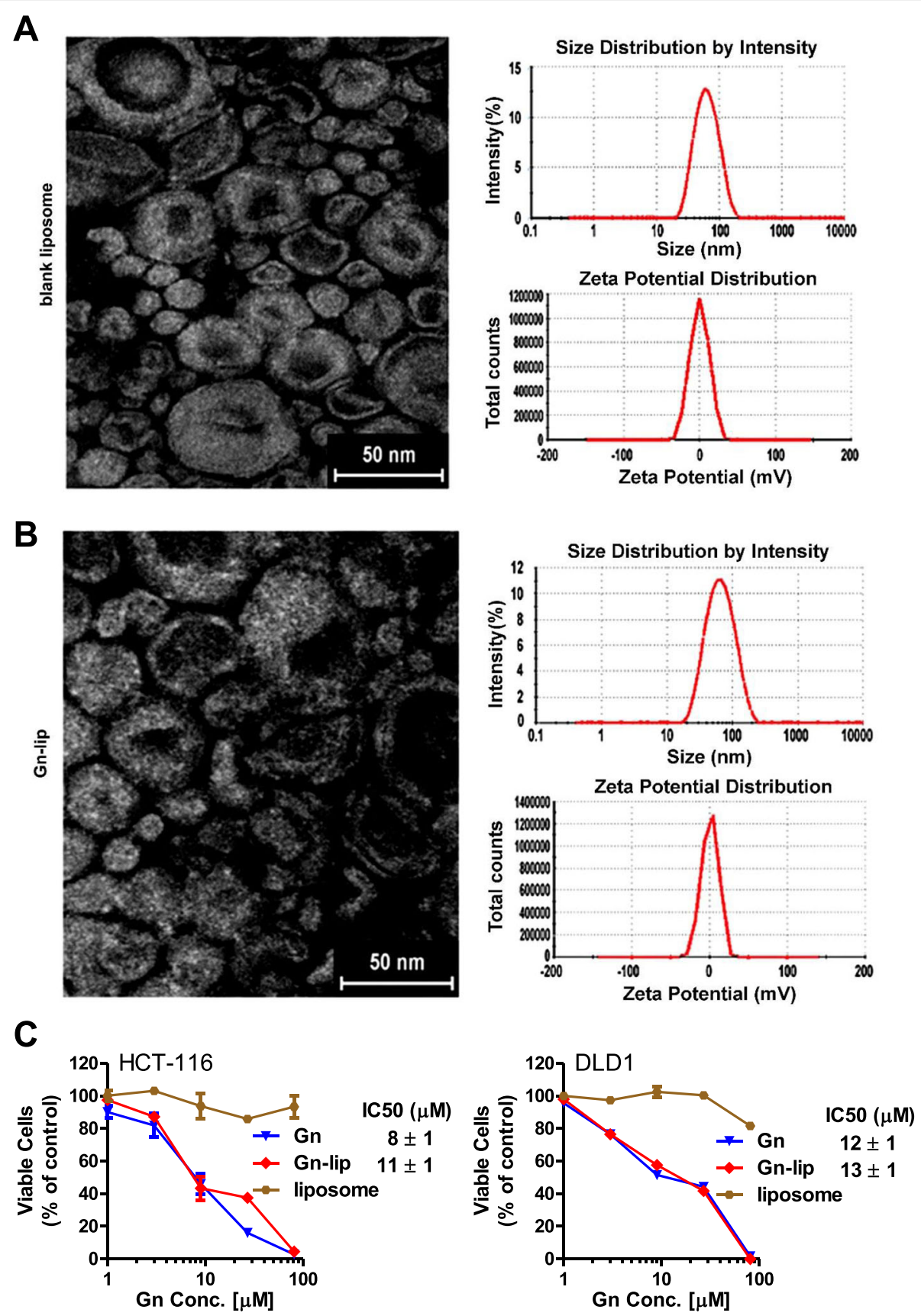

Fig. 5 Characterization of gossypolone-liposomes (Gn-lip). a TEM image (left), size distribution (upper right), and Zeta-potential (lower right) of blank liposomes. b TEM image (left), size distribution (upper right), and Zeta-potential (lower right) of Gn-loaded liposomes. c MTT-based cytotoxicity assay of free $\mathrm{Gn}$, encapsulated $\mathrm{Gn}(\mathrm{Gn}$-lip), and the liposomes with the same concentrations of vehicle in $\mathrm{Gn}$-lip using selected colon cancer cell lines ( $\mathrm{n}=3$ ). Gn-lip and Gn showed similar cell viability profiles; while the liposomes alone did not show evident cytotoxicity within the investigated concentrations

the particle size $(55.89 \pm 0.34 \mathrm{~nm})$ of fresh sample. This result demonstrated a good size stability of Gn-lip.

The viabilities of cells in the presence of free $\mathrm{Gn}$ or Gn-lip were similar, for both HCT-116 and DLD-1 cells (Fig. 5c). The $\mathrm{IC}_{50}$ value of free $\mathrm{Gn}$ and $\mathrm{Gn}$-lip were $12 \mu \mathrm{M}$ and $13 \mu \mathrm{M}$ for DLD-1 cell, respectively, and were $8 \mu \mathrm{M}$ and $11 \mu \mathrm{M}$ for HCT-116 cell, respectively.
Although the $\mathrm{IC}_{50}$ values of $\mathrm{Gn}$-lip was a little higher than that of free $\mathrm{Gn}$, cytotoxicity of $\mathrm{Gn}$ was not significantly compromised by encapsulation. The increased $\mathrm{IC}_{50}$ values of $\mathrm{Gn}$-lip might be due to the sustained release of $\mathrm{Gn}$ from the liposomes.

The in vivo tumor-specific accumulation of the liposomes was confirmed using DLD-1 tumor-bearing SCID mice. In 
the mouse that was given NIR dye-loaded liposomes, DiR signal increased in the tumor regions over time and became the strongest $24 \mathrm{~h}$ after the injection (Fig. 6a). DiR signal was much weaker in control mouse that was given free DiR at the same time, due to non-specific distribution, fast clearance, and quenching of free DiR molecules. The ex vivo imaging results were shown in Fig. 6b, and the fluorescence \%ID/g tissue is shown in Fig. 6c. Compared with in vivo imaging, ex vivo imaging does not have the masking effects of the skin and hairs on the fluorescence. Consistent with the in vivo results, quantifications using $\% \mathrm{ID} / \mathrm{g}$ also showed more DiR in tumors of DiR-lip group than in tumors of free DiR group. In addition, more DiR existed in the liver of free DiR group. Since liver is the main organ for Gn metabolism, this result indicates that the drug in liposomes may have a long-term effect as compared with the free drug. The results are also consistent with our previous findings, which indicated the elongated retention and protection of DiR in the body brought about by the encapsulation of liposomes [77].

\section{In vivo drug efficacy of Gn in DLD-1 tumor-bearing nude mice}

The in vivo tumor suppression effect of Gn-lip was compared with vehicle control (Fig. 7a). Significant tumor growth inhibition was observed in Gn-lip group compared with the vehicle $(P<0.01)$. Gn-lip also showed better efficacy compared to gossypol treated group (Additional file 1: Figure S2). The mice body weight of Gn group kept stable during the whole experimental time (Fig. 7b), indicating the low systemic toxicity of Gn-lip treatment. To investigate whether Gn induces apoptosis and inhibit Notch/Wnt signaling in tumors, tumor samples were collected and processed for western blotting analysis. With Gn-lip treatment, there was an increase in PARP cleavage, indication of apoptosis (Fig. 7c, left panel). We also probed the Gn-lip

A

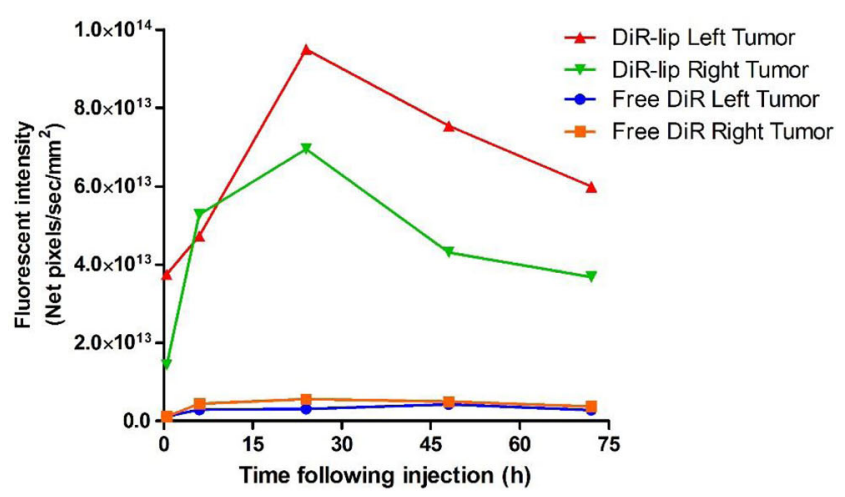

B

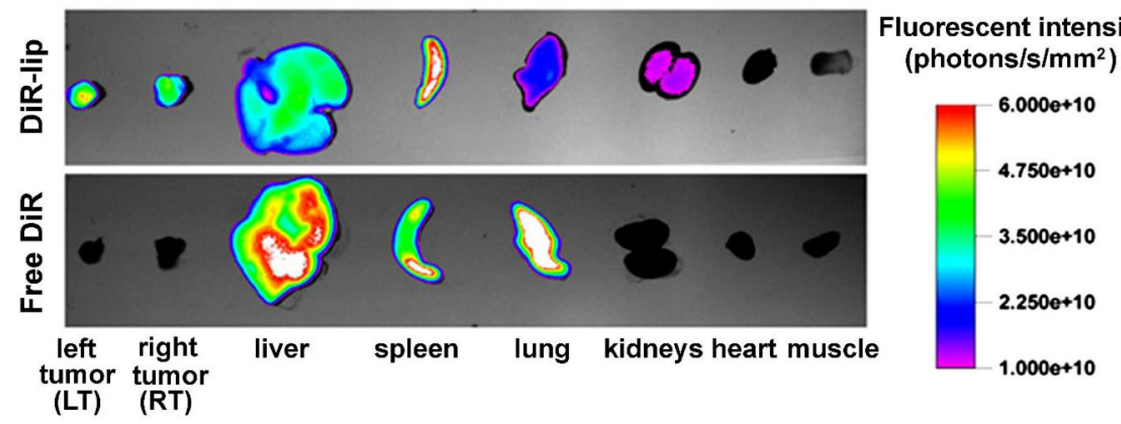

C

\begin{tabular}{lcc}
\multicolumn{3}{c}{$\%$ ID/g tissue $(\%)$} \\
\hline Tissues & Free DiR & DiR-lip \\
\hline Left tumor & 0.97 & 13.34 \\
Right tumor & 1.39 & 14.94 \\
Liver & 0.7 & 0.47 \\
\hline
\end{tabular}

Fig. 6 NIR imaging and biodistribution of DiR-loaded liposomes (DiR-lip) in SCID mouse bearing DLD-1 tumor. a In vivo DiR fluorescent intensity in tumors of mice. $\mathbf{b}$ Ex vivo NIR images of tumors and different organs of each mouse. $\mathbf{c} \% \mathrm{ID} / \mathrm{g}$ tissue (\%) for tumor and liver. Compared with control mouse, DiR in liposomes tended to accumulate in tumors rather than liver and other organs of mouse 

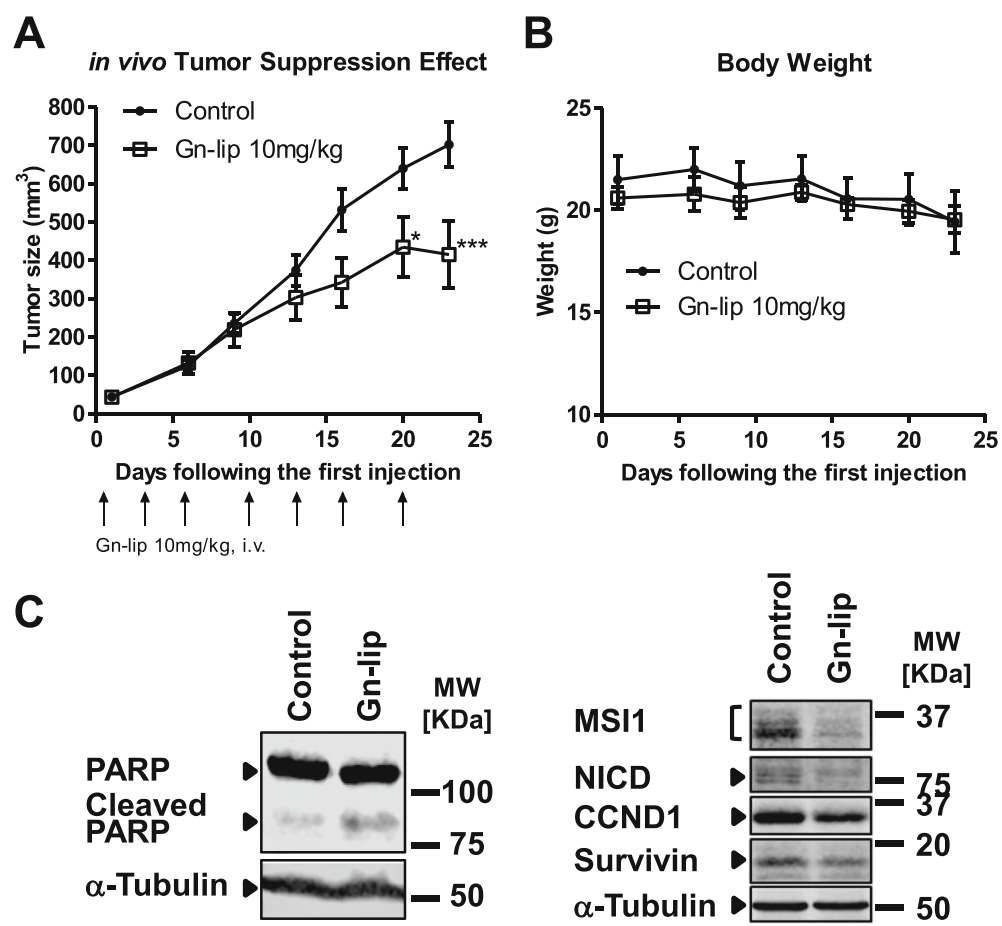

D

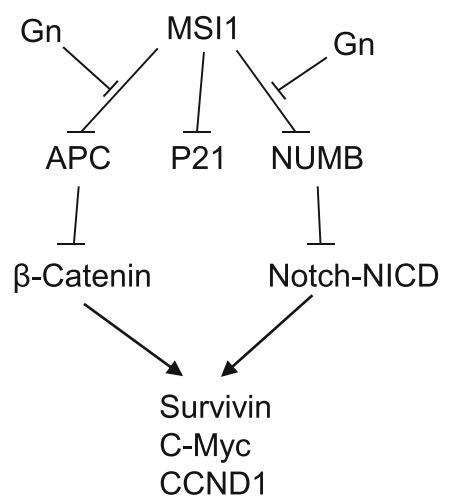

Fig. 7 Gn-lip inhibited DLD-1 xenograft growth. Tail vein injection of Gn-lip inhibited DLD1 xenograft growth and was associated with decreased Notch/Wnt signaling and increased apoptosis. a Gn potently inhibited the DLD-1 xenograft tumor growth in nude mice as a single-agent therapy. The data shown are average tumor size (means \pm S.E.M., $n=10)$ versus control $(n=20)$. ${ }^{* *} p<0.01$ b Body weight of both groups remained similar during the treatment time, indicating a low systemic toxicity of Gn-lip. c Gn-lip induced apoptosis and down-regulated several Notch/Wnt downstream genes in tumor samples. d Working model

treatment group for several Notch/Wnt downstream targets, as shown in Fig. 7c right panel, Gn-lip treatment led to decreases in MSI1, activated Notch, CYCLIN D1 and SURVIVIN protein levels, indication of decreased Notch/ Wnt signaling in the tumor tissues. Overall, Gn loaded in the liposomes had a significant tumor inhibition efficacy and a good biocompatibility; it also induced apoptosis and inhibited Notch/Wnt signaling in tumors.

\section{Discussion}

In this study, we sought to identify additional small molecule inhibitors of Musashi-1(MSI1). Such inhibitors can downregulate Notch/Wnt signaling and block cell cycle progression through MSI1. To this end, we used FP-based screening and identified $\mathrm{Gn}$ as a potential MSI1 inhibitor. We further confirmed Gn binding to MSI1 using SPR and using NMR, identified the amino acids in the RNA-Recognition Motif 1 that were involved in the binding. Using colon cancer cell lines, we showed that Gn inhibited cell growth, induced autophagy, inhibited Notch/Wnt signaling in these cells and led to apoptotic cell death. However, compared to $10 \mu \mathrm{M}(-)$-gossypol [27], the same concentration of $\mathrm{Gn}$ was less active in cell assays. This result could be due to poor water-solubility of $\mathrm{Gn}$. Therefore, 
we used a liposomal carrier to deliver $\mathrm{Gn}$ in animals. The liposome could efficiently increase the apparent solubility of $\mathrm{Gn}$ in water. We showed that $\mathrm{Gn}$ loaded liposomes induced apoptosis, inhibited tumor growth and Notch/Wnt signaling in DLD-1 xenograft model. Our study identified a new target for $\mathrm{Gn}$ and provided a new delivery method for this poorly bioavailable compound.

MSI1 is an RNA-binding protein that promotes cell proliferation and survival through Notch/Wnt signaling (Fig. 7d). Inhibiting MSI1 is a promising therapeutic strategy for preventing cancer cell proliferation and progression. Here we identified $\mathrm{Gn}$ as a more potent inhibitor of MSI1 compared to (-)-gossypol [27] in our binding assays. Our NMR studies showed that Gn bound to the same residues as the cognate RNA. The NMR peaks of the RNA-binding residues (K93, F23 and W29) showed the most changes upon titration of Gn (Fig. 1c). This suggests that these residues are involved in the binding to $\mathrm{Gn}$, consistent with our docked model. The majority of non-RNA binding residues were unaffected when titrated with $\mathrm{Gn}$, suggesting that the interaction between $\mathrm{Gn}$ and MSI1-RBD1 tends to be more localized near the RNA binding pocket as compared to the binding event between (-)-gossypol and MSI1-RBD1 [27]. This might explain the improved potency of Gn compared to (-)-gossypol. Additional X-ray crystallography studies will be helpful in determining the high resolution structure of the complex between MSI1-RBD1 and Gn.

Based on the sequence identity of RBDs/RRMs of MSI1 and MSI2, we tested the binding of Gn towards MSI2 and showed that Gn can disrupt the binding of MSI2 to Numb RNA. Like MSI1, MSI2 is also a member of the Musashi family of RNA-binding protein and shares similar roles as MSI1 in stem cells $[28,29]$. In colorectal cancer initiation and maintenance, a recent study demonstrated the functional redundancy between MSI1 and MSI2 [78]. Thus using a MSI1/MSI2 dual inhibitor such as Gn in patients with MSI overexpression suggests an improved therapeutic outcome.

The introduction of PEGylated liposomes improved the dispersion of $\mathrm{Gn}$ in aqueous environment, thus making it possible to produce injectable drug solutions, which is essential for a better bioavailability of $\mathrm{Gn}$. As shown in the results of MTT assay (Fig. 5c), the encapsulation of Gn using liposomes did not compromise the cytotoxicity of $\mathrm{Gn}$ in vitro. Finally, the Gn-lip exhibited a significant tumor inhibition efficacy and a low systemic toxicity in the mice. Our work is important in that our study provides a proof-of-concept to develop the Gn-lip as a novel molecular therapy for colon cancer with MSI overexpression.

The limitation of our current inhibitors is that they are not specific to MSI1/MSI2, because Gn and the previously reported (-)-gossypol [27] are both Bcl-2 family inhibitors as well $[46-52,62,63,76,79]$. With Gn treatment, we saw apoptosis/autophagy induction via Bcl-2 and cell proliferation inhibition via Wnt and/or Notch signaling pathways. Our goal is to develop potent and specific MSI1/MSI2 inhibitors, and ultimately move these new inhibitors into clinical applications in the treatment of cancers with MSI overexpression. Towards this goal, our future efforts will focus on utilizing computer modeling and medicinal chemistry for identifying new chemical scaffolds that selectively inhibit MSI1/2.

\section{Conclusions}

Gn was identified as a MSI1/2 duo inhibitor in this study. It disrupted binding of MSI1 to its target mRNAs by binding to the RBD1 of MSI1. Gn inhibited colon cancer cell growth, induced autophagy, down-regulated Notch/Wnt signaling and led to apoptotic cell death. The introduction of tumor-targeted liposomes significantly improved the bioavailability of $\mathrm{Gn}$, meanwhile maintaining its drug efficacy. Gn-lip has promising antitumor effects and biocompatibility in vivo, warranting further study to determine its suitability for cancer treatment.

\section{Additional files}

Additional file 1: Figure S1. MSI1 and NUMB protein levels in HCT-116 $\beta / W$ CRISPR clone cell lines. Figure S2. In vivo tumor suppression effect. (PPTX $548 \mathrm{~kb}$ )

Additional file 2: Video 1. (AVI $2064 \mathrm{~kb})$

Additional file 3: Video 2. (AVI $2645 \mathrm{~kb})$

\section{Abbreviations}

APC: Adenomatous polyposis coli; CETSA: Cellular thermal shift assay; CQ: Chloroquine; DLC: Drug loading content; DLE: Drug loading efficiency; DLS: Dynamic Light Scattering; FP: Fluorescence polarization; Gn: gossypolone; Gn-lip: Gn-loaded liposomes; MP-Gr: (3, 4-Dimethoxyphenyl) methanimine gossypol; NIR: Near-infrared; NMR: Nuclear magnetic resonance; RBD: RNABinding Domain; RRMs: RNA Recognition Motifs; SPR: Surface plasmon resonance; TEM: Transmission electron microscopy

\section{Acknowledgements}

We are grateful to OpenEye Scientific Software (Santa Fe, NM) for providing an academic license for the use of OMEGA, ROCS, MolProp, and QuacPac. We thank the NCI/DTP Open Chemical Repository (http://dtp.cancer.gov) libraries.

\section{Funding}

This study was supported in part by National Institutes of Health grants R01 CA178831 and CA191785 (to LX, JA, KN); Al074856 (to R.N.D.); NIH COBRE-PSF at KU (P30 GM110761) Pilot Project, Department of Defense Breast Cancer Research Program Breakthrough Level II grant BC151845, and Kansas Bioscience Authority Rising Star Award (to LX). No involvement of the funding bodies in any part of the study.

\section{Availability of data and materials}

The datasets used and/or analyzed during the current study are available from the corresponding author on reasonable request.

\section{Authors' contributions}

$L L, H L$, and $L X$ contributed to conception and design of the study. $L L, H L$, $A S, C A, J Y, S L, R M$ and $P G$ acquired and analyzed the data. $L L, H L, A S, R M, K L$, $R G, J K, R N D, J A, K N$ and $L X$ interpreted data. $L L$ and $H L$ drafted the manuscript; $L L, H L, A S, J K, R N D, J A, K N$ and $L X$ revised it critically for important intellectual content. All authors gave final approval of the version to be published. $\mathrm{LL}$ and $\mathrm{HL}$ contributed equally to this work. 


\section{Ethics approval and consent to participate}

None of the cell lines used in this study require ethics approval for their use. All animal experiments were carried out according to the protocol approved by the Institutional Committee for the Use and Care of Animals of University of Kansas.

\section{Consent for publication}

Not applicable.

\section{Competing interests}

The authors declare that they have no competing interests.

\section{Publisher's Note}

Springer Nature remains neutral with regard to jurisdictional claims in published maps and institutional affiliations.

\section{Author details}

'Departments of Molecular Biosciences, University of Kansas, 4002 Haworth Hall, 1200 Sunnyside Avenue, Lawrence, KS 66045-7534, USA. ²Protein Production Group, NIH COBRE in Protein Structure and Function, Lawrence, USA. ${ }^{3}$ Center for Computational Biology, University of Kansas, Lawrence, Kansas, USA. ${ }^{4}$ School of Chemistry and Chemical Engineering, Southeast University, Nanjing, China. ${ }^{5}$ Program in Molecular Therapeutics, Fox Chase Cancer Center, Philadelphia, PA, USA. ${ }^{6}$ Eshelman School of Pharmacy, University of North Carolina, Chapel Hill, NC, USA. ${ }^{7}$ Department of Radiation Oncology, University of Kansas Cancer Center, Kansas City, Kansas, USA. ${ }^{8}$ Current address: School of Pharmacy, Southwest Medical University, Luzhou City, China.

Received: 17 January 2018 Accepted: 30 July 2018

Published online: 10 August 2018

\section{References}

1. Toda M, lizuka Y, Yu W, Imai T, Ikeda E, Yoshida K, Kawase T, Kawakami Y, Okano $\mathrm{H}$, Uyemura $\mathrm{K}$. Expression of the neural RNA-binding protein Musashi1 in human gliomas. Glia. 2001;34(1):1-7.

2. Potten CS, Booth C, Tudor GL, Booth D, Brady G, Hurley P, Ashton G, Clarke $\mathrm{R}$, Sakakibara S, Okano H. Identification of a putative intestinal stem cell and early lineage marker; musashi-1. Differentiation. 2003;71(1):28-41.

3. Sureban SM, May R, George RJ, Dieckgraefe BK, McLeod HL, Ramalingam S, Bishnupuri KS, Natarajan G, Anant S, Houchen CW. Knockdown of RNA Binding Protein Musashi-1 Leads to Tumor Regression In Vivo. Gastroenterology. 2008;134(5):1448-58. e1442

4. Wang X-Y, Penalva L, Yuan H, Linnoila Rl, Lu J, Okano H, Glazer R. Musashir regulates breast tumor cell proliferation and is a prognostic indicator of poor survival. Mol Cancer. 2010;9(1):221.

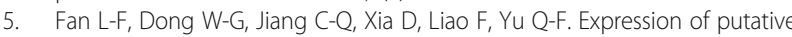
stem cell genes Musashi-1 and $\beta 1$-integrin in human colorectal adenomas and adenocarcinomas. Int J Color Dis. 2010;25(1):17-23.

6. Ma Y-H, Mentlein R, Knerlich F, Kruse M-L, Mehdorn H, Held-Feindt J. Expression of stem cell markers in human astrocytomas of different WHO grades. J Neuro-Oncol. 2008;86(1):31-45.

7. Seigel GM, Hackam A, Ganguly A, Mandell L, Gonzalez-Fernandez F. Human embryonic and neuronal stem cell markers in retinoblastoma. Mol Vis. 2007; 13:823-32.

8. Ye F, Zhou C, Cheng Q, Shen J, Chen H. Stem-cell-abundant proteins Nanog, Nucleostemin and Musashi1 are highly expressed in malignant cervical epithelial cells. BMC Cancer. 2008;8(1):108.

9. Yokota N, Mainprize TG, Taylor MD, Kohata T, Loreto M, Ueda S, Dura W, Grajkowska W, Kuo JS, Rutka JT. Identification of differentially expressed and developmentally regulated genes in medulloblastoma using suppression subtraction hybridization. Oncogene. 2004;23(19):3444-53.

10. Wang XY, Yu H, Linnoila RI, Li L, Li D, Mo B, Okano H, Penalva LO, Glazer Rl. Musashi1 as a potential therapeutic target and diagnostic marker for lung cancer. Oncotarget. 2013:4(5):739-50.

11. Li D, Peng X, Yan D, Tang H, Huang F, Yang Y, Peng Z. Msi-1 is a predictor of survival and a novel therapeutic target in colon cancer. Ann Surg Oncol. 2011:18(7):2074-83.

12. Hou $T$, Zhang $W$, Tong $C$, Kazobinka $G$, Huang $X$, Huang $Y$, Zhang $Y$. Putative stem cell markers in cervical squamous cell carcinoma are correlated with poor clinical outcome. BMC Cancer. 2015;15:785.
13. Nakamura M, Okano H, Blendy JA, Montell C. Musashi, a neural RNA-binding protein required for Drosophila adult external sensory organ development. Neuron. 1994;13(1):67-81.

14. Sakakibara S, Imai T, Hamaguchi K, Okabe M, Aruga J, Nakajima K, Yasutomi D, Nagata T, Kurihara Y, Uesugi S, et al. Mouse-Musashi-1, a neural RNAbinding protein highly enriched in the mammalian CNS stem cell. Dev Biol. 1996;176(2):230-42.

15. Kaneko Y, Sakakibara S, Imai T, Suzuki A, Nakamura Y, Sawamoto K, Ogawa Y, Toyama Y, Miyata T, Okano H. Musashi1: an evolutionally conserved marker for CNS progenitor cells including neural stem cells. Dev Neurosci. 2000;22(1-2):139-53.

16. Charlesworth A, Wilczynska A, Thampi P, Cox LL, MacNicol AM. Musashi regulates the temporal order of mRNA translation during Xenopus oocyte maturation. EMBO J. 2006;25(12):2792-801.

17. Sugiyama-Nakagiri Y, Akiyama M, Shibata S, Okano H, Shimizu H. Expression of RNA-binding protein Musashi in hair follicle development and hair cycle progression. Am J Pathol. 2006;168(1):80-92.

18. Glazer RI, Vo DT, Penalva LO. Musashi1: an RBP with versatile functions in normal and cancer stem cells. Front Biosci. 2012:17:54-64.

19. Spears E, Neufeld KL. Novel double-negative feedback loop links adenomatous polyposis coli and Musashi in colon epithelia. J Biol Chem. 2011;286(7):4946-50.

20. Kawahara H, Imai T, Imataka H, Tsujimoto M, Matsumoto K, Okano H. Neura RNA-binding protein Musashi1 inhibits translation initiation by competing with elF4G for PABP. J Cell Biol. 2008;181(4):639-53.

21. Battelli C, Nikopoulos GN, Mitchell JG, Verdi JM. The RNA-binding protein Musashi-1 regulates neural development through the translational repression of p21WAF-1. Mol Cell Neurosci. 2006;31(1):85-96.

22. Imai T, Tokunaga A, Yoshida T, Hashimoto M, Mikoshiba K, Weinmaster G, Nakafuku M, Okano H. The neural RNA-binding protein Musashi1 translationally regulates mammalian numb gene expression by interacting with its mRNA. Mol Cell Biol. 2001:21(12):3888-900

23. Takahashi T, Suzuki H, Imai T, Shibata S, Tabuchi Y, Tsuchimoto K, Okano H, Hibi T. Musashi-1 post-transcriptionally enhances phosphotyrosine-binding domain-containing $m$-numb protein expression in regenerating gastric mucosa. PLoS One. 2013:8(1):e53540.

24. Pece S, Serresi M, Santolini E, Capra M, Hulleman E, Galimberti V, Zurrida S, Maisonneuve P, Viale G, Di Fiore PP. Loss of negative regulation by numb over notch is relevant to human breast carcinogenesis. J Cell Biol. 2004; 167(2):215-21.

25. Moon RT, Miller JR. The APC tumor suppressor protein in development and cancer. Trends in genetics : TIG. 1997;13(7):256-8.

26. Smith AR, Marquez RT, Tsao WC, Pathak S, Roy A, Ping J, Wilkerson B, Lan L, Meng W, Neufeld KL, et al. Tumor suppressive microRNA-137 negatively regulates Musashi-1 and colorectal cancer progression. Oncotarget. 2015; 6(14):12558-73.

27. Lan L, Appelman C, Smith AR, Yu J, Larsen S, Marquez RT, Liu H, Wu X, Gao $P$, Roy $A$, et al. Natural product (-)-gossypol inhibits colon cancer cell growth by targeting RNA-binding protein Musashi-1. Mol Oncol. 2015

28. Sakakibara S, Nakamura Y, Yoshida T, Shibata S, Koike M, Takano H, Ueda S, Uchiyama Y, Noda T, Okano H. RNA-binding protein Musashi family: roles for CNS stem cells and a subpopulation of ependymal cells revealed by targeted disruption and antisense ablation. Proc Natl Acad Sci U S A. 2002: 99(23):15194-9.

29. Sakakibara S, Nakamura Y, Satoh H, Okano H. Rna-binding protein Musashiz: developmentally regulated expression in neural precursor cells and subpopulations of neurons in mammalian CNS. J Neurosci. 2001;21 (20):8091-107.

30. Kharas MG, Lengner CJ, Al-Shahrour F, Bullinger L, Ball B, Zaidi S, Morgan K, Tam W, Paktinat M, Okabe R, et al. Musashi-2 regulates normal hematopoiesis and promotes aggressive myeloid leukemia. Nat Med. 2010; 16(8):903-8.

31. Ito T, Kwon HY, Zimdahl B, Congdon KL, Blum J, Lento WE, Zhao C, Lagoo $A$, Gerrard G, Foroni L, et al. Regulation of myeloid leukaemia by the cellfate determinant Musashi. Nature. 2010:466(7307):765-8.

32. Aly RM, Ghazy HF. Prognostic significance of MSI2 predicts unfavorable outcome in adult B-acute lymphoblastic leukemia. Int J Lab Hematol. 2015: 37(2):272-8

33. Kaeda J, Ringel F, Oberender C, Mills K, Quintarelli C, Pane F, Koschmieder S, Slany R, Schwarzer R, Saglio G, et al. Up-regulated MSI2 is associated with more aggressive chronic myeloid leukemia. Leuk Lymphoma. 2015:56(7): 2105-13. 
34. Thol F, Winschel C, Sonntag AK, Damm F, Wagner K, Chaturvedi A, Gohring G, Schlegelberger B, Lubbert M, Fiedler W, et al. Prognostic significance of expression levels of stem cell regulators MSI2 and NUMB in acute myeloid leukemia. Ann Hematol. 2013;92(3):315-23.

35. Byers RJ, Currie T, Tholouli E, Rodig SJ, Kutok JL. MSI2 protein expression predicts unfavorable outcome in acute myeloid leukemia. Blood. 2011;118(10):2857-67.

36. Griner LN, Reuther GW. Aggressive myeloid leukemia formation is directed by the Musashi 2/numb pathway. Cancer biology \& therapy. 2010;10(10):979-82

37. Shan W, Ning L, Maryam Y, Angela N-D, Fan L, Kimberly P, Shilpa R, Gerard $M$, Yarden K, Brian DG, et al. Transformation of the intestinal epithelium by the MSI2 RNA-binding protein. Nat Commun. 2015;6

38. Kudinov AE, Deneka A, Nikonova AS, Beck TN, Ahn YH, Liu X, Martinez CF, Schultz FA, Reynolds S, Yang DH, et al. Musashi-2 (MSI2) supports TGF-beta signaling and inhibits claudins to promote non-small cell lung cancer (NSCLC) metastasis. Proc Natl Acad Sci U S A. 2016;113(25):6955-60.

39. Sheng W, Dong M, Chen C, Wang Z, Li Y, Wang K, Li Y, Zhou J. Cooperation of Musashi-2, numb, MDM2, and P53 in drug resistance and malignant biology of pancreatic cancer. FASEB J. 2017;

40. Guo K, Cui J, Quan M, Xie D, Jia Z, Wei D, Wang L, Gao Y, Ma Q, Xie K. The novel KLF4/MSI2 signaling pathway regulates growth and metastasis of pancreatic Cancer. Clin Cancer Res. 2017;23(3):687-96.

41. Fox RG, Lytle NK, Jaquish DV, Park FD, Ito T, Bajaj J, Koechlein CS, Zimdahl B, Yano M, Kopp JL, et al. Image-based detection and targeting of therapy resistance in pancreatic adenocarcinoma. Nature. 2016;534(7607):407-11.

42. Cox JL, Wilder PJ, Gilmore JM, Wuebben EL, Washburn MP, Rizzino A. The SOX2-interactome in brain cancer cells identifies the requirement of MSI2 and USP9X for the growth of brain tumor cells. PLOS One. 2013;8(5):e62857.

43. Ohyama T, Nagata T, Tsuda K, Kobayashi N, Imai T, Okano H, Yamazaki T, Katahira M. Structure of Musashi1 in a complex with target RNA: the role of aromatic stacking interactions. Nucleic Acids Res. 2012;40(7):3218-31.

44. Haas RHS, D. A. The oxidation of gossypol. II. Formation of gossypolone with ferric chloride. J Org Chem. 1965:30:4111-3.

45. YW Y. Probing into the mechanism of action, metabolism and toxicity of gossypol by studying its (+)- and (-)-stereoisomers. J Ethnopharmacol. 1987; 20(1):65-78

46. Shelley MD, Hartley L, Fish RG, Groundwater P, Morgan JJ, Mort D, Mason M, Evans A. Stereo-specific cytotoxic effects of gossypol enantiomers and gossypolone in tumour cell lines. Cancer Lett. 1999:135(2):171-80.

47. Blackstaffe L, Shelley MD, Fish RG. Cytotoxicity of gossypol enantiomers and its quinone metabolite gossypolone in melanoma cell lines. Melanoma Res. 1997;7(5):364-72.

48. Gilbert NE, O'Reilly JE, Chang CJ, Lin YC, Brueggemeier RW. Antiproliferative activity of gossypol and gossypolone on human breast cancer cells. Life Sci. 1995:57(1):61-7.

49. Shaomeng Wang DY, Liang Xu: Small molecule antagonists of Bcl-2 family proteins (US patent 8163805 B2). In., vol. US8163805 B2.

50. Farid A, Badria WEH, Mona G, Zaghloul AF. Halim: antimitotic activity of gossypol and Gossypolone. Pharm Biol. 2001;39(2):120-6.

51. Kim IC, Waller DP, Marcelle GB, Cordell GA, Fong HH, Pirkle WH, Pilla L, Matlin SA. Comparative in vitro spermicidal effects of (+/-)-gossypol, (+)-gossypol, (-)-gossypol and gossypolone. Contraception. 1984;30(3):253-9.

52. Gu Y, Lin YC. Suppression of adrenocorticotropic hormone (ACTH)-induced corticosterone secretion in cultured rat adrenocortical cells by gossypol and gossypolone. Res Commun Chem Pathol Pharmacol. 1991;72(1):27-38.

53. Park JW. Liposome-based drug delivery in breast cancer treatment. Breast cancer research : BCR. 2002;4(3):95-9.

54. Baek SE, Lee KH, Park YS, Oh DK, Oh S, Kim KS, Kim DE. RNA aptamerconjugated liposome as an efficient anticancer drug delivery vehicle targeting cancer cells in vivo. J controlled release : official journal of the Controlled Release Society. 2014;196:234-42.

55. Katanasaka Y, Ishii T, Asai T, Naitou H, Maeda N, Koizumi F, Miyagawa S, Ohashi N, Oku N. Cancer antineovascular therapy with liposome drug delivery systems targeted to BiP/GRP78. International journal of cancer Journal international du cancer. 2010;127(11):2685-98.

56. Wu D, Wan M. Methylene diphosphonate-conjugated adriamycin liposomes: preparation, characteristics, and targeted therapy for osteosarcomas in vitro and in vivo. Biomed Microdevices. 2012;14(3):497-510.

57. Hsu WH, Liu SY, Chang YJ, Chang CH, Ting G, Lee TW. The PEGylated liposomal doxorubicin improves the delivery and therapeutic efficiency of 188Re-liposome by modulating phagocytosis in C26 murine colon carcinoma tumor model. Nucl Med Biol. 2014;41(9):765-71.
58. Yang T, Cui FD, Choi MK, Cho JW, Chung SJ, Shim CK, Kim DD. Enhanced solubility and stability of PEGylated liposomal paclitaxel: in vitro and in vivo evaluation. Int J Pharm. 2007;338(1-2):317-26.

59. Gabizon A, Martin F. Polyethylene glycol-coated (pegylated) liposomal doxorubicin. Rationale for use in solid tumours. Drugs. 1997;54(Suppl 4):15-21.

60. Uphoff CC, Drexler HG. Detecting mycoplasma contamination in cell cultures by polymerase chain reaction. Methods Mol Biol. 2011;731:93-103.

61. Dodou K, Anderson RJ, Lough WJ, Small DA, Shelley MD, Groundwater PW. Synthesis of gossypol atropisomers and derivatives and evaluation of their antiproliferative and anti-oxidant activity. Bioorg Med Chem. 2005;13(13):4228-37.

62. Lian J, Wu X, He F, Karnak D, Tang W, Meng Y, Xiang D, Ji M, Lawrence TS, $\mathrm{Xu}$ L. A natural BH3 mimetic induces autophagy in apoptosis-resistant prostate cancer via modulating $\mathrm{BCl}-2-$-Beclin1 interaction at endoplasmic reticulum. Cell Death Differ. 2011;18(1):60-71.

63. Meng $Y$, Tang W, Dai $Y$, Wu X, Liu M, Ji O, Ji M, Pienta K, Lawrence T, Xu L. Natural BH3 mimetic (-)-gossypol chemosensitizes human prostate cancer via $\mathrm{BCl}-\mathrm{xL}$ inhibition accompanied by increase of Puma and Noxa. Mol Cancer Ther. 2008;7(7):2192-202.

64. Wu X, Li M, Qu Y, Tang W, Zheng Y, Lian J, Ji M, Xu L. Design and synthesis of novel Gefitinib analogues with improved anti-tumor activity. Bioorg Med Chem. 2010;18(11):3812-22.

65. Li L, Hao X, Qin J, Tang W, He F, Smith A, Zhang M, Simeone DM, Qiao XT, Chen ZN, et al. Antibody against CD44s inhibits pancreatic tumor initiation and post-radiation recurrence in mice. Gastroenterology. 2014;146(4):11.

66. Li L, Tang W, Wu X, Karnak D, Meng X, Thompson R, Hao X, Li Y, Qiao XT, Lin J, et al. HAb18G/CD147 promotes pSTAT3-mediated pancreatic cancer development via CD44s. Clin Cancer Res. 2013;19(24):6703-15.

67. Morris GM, Huey R, Lindstrom W, Sanner MF, Belew RK, Goodsell DS, Olson AJ. AutoDock4 and AutoDockTools4: automated docking with selective receptor flexibility. J Comput Chem. 2009;30(16):2785-91.

68. Martinez Molina D, Jafari R, Ignatushchenko M, Seki T, Larsson EA, Dan C, Sreekumar L, Cao Y, Nordlund P. Monitoring drug target engagement in cells and tissues using the cellular thermal shift assay. Science. 2013; 341(6141):84-7.

69. Liu H, Li K, Xu L, Wu DC. Bilayered near-infrared fluorescent nanoparticles based on low molecular weight PEl for tumor-targeted in vivo imaging. J Nanopart Res. 2014:16(12).

70. Liu H, Li K, Lan L, Ma JW, Zeng Y, Xu L, Wu DC. Double-layered hyaluronic acid/ stearic acid-modified polyethyleneimine nanoparticles encapsulating (-)-gossypol: a nanocarrier for chiral anticancer drugs. J Mater Chem B. 2014;2(32):5238-48.

71. Rezza A, Skah S, Roche C, Nadjar J, Samarut J, Plateroti M. The overexpression of the putative gut stem cell marker Musashi-1 induces tumorigenesis through Wnt and notch activation. J Cell Sci. 2010;123(Pt 19):3256-65.

72. Klionsky DJ, Abdelmohsen K, Abe A, Abedin MJ, Abeliovich H, Acevedo Arozena A, Adachi H, Adams CM, Adams PD, Adeli K, et al. Guidelines for the use and interpretation of assays for monitoring autophagy (3rd edition). Autophagy. 2016;12(1):1-222.

73. Shintani T, Klionsky DJ. Autophagy in health and disease: a double-edged sword. Science. 2004;306(5698):990-5.

74. Zhang M, Liu H, Guo R, Ling Y, Wu X, Li B, Roller PP, Wang S, Yang D. Molecular mechanism of gossypol-induced cell growth inhibition and cell death of HT-29 human colon carcinoma cells. Biochem Pharmacol. 2003:66(1):93-103.

75. Zhang XQ, Huang XF, Mu SJ, An QX, Xia AJ, Chen R, Wu DC. Inhibition of proliferation of prostate cancer cell line, $\mathrm{PC}-3$, in vitro and in vivo using (-)-gossypol. Asian journal of andrology. 2010;12(3):390-9.

76. Paoluzzi L, Gonen M, Gardner JR, Mastrella J, Yang D, Holmlund J, Sorensen M, Leopold L, Manova K, Marcucci G, et al. Targeting Bcl-2 family members with the BH3 mimetic AT-101 markedly enhances the therapeutic effects of chemotherapeutic agents in in vitro and in vivo models of B-cell lymphoma. Blood. 2008;111(11):5350-8.

77. Li K, Liu H, Gao W, Chen M, Zeng Y, Liu J, Xu L, Wu D. Mulberry-like dualdrug complicated nanocarriers assembled with apogossypolone amphiphilic starch micelles and doxorubicin hyaluronic acid nanoparticles for tumor combination and targeted therapy. Biomaterials. 2015;39:131-44.

78. Li N, Yousefi M, Nakauka-Ddamba A, Li F, Vandivier L, Parada K, Woo DH, Wang S, Naqvi AS, Rao S, et al. The Msi family of RNA-binding proteins function redundantly as intestinal Oncoproteins. Cell Rep. 2015;13(11):2440-55.

79. Oliver CL, Bauer JA, Wolter KG, Ubell ML, Narayan A, O'Connell KM, Fisher SG, Wang S, Wu X, Ji M, et al. In vitro effects of the BH3 mimetic, (-)-gossypol, on head and neck squamous cell carcinoma cells. Clin Cancer Res. 2004;10(22): 7757-63. 